\title{
Evaluating malnutrition management through an intersectional lens: A case study of a community-based child malnutrition program in rural Uganda
}

\author{
AUTHORS: Marie-Catherine Gagnon-Dufresne ${ }^{1,2}$, Geneviève Fortin ${ }^{1,2}$, Kirsten \\ Bunkeddeko $^{3}$, Charles Kalumuna ${ }^{3}$, Kate Zinszer ${ }^{1,2}$ \\ 1. University of Montreal's School of Public Health (Montreal, Canada) \\ 2. Centre for Public Health Research, CReSP (Montreal, Canada) \\ 3. Soft Power Health (Kyabirwa, Uganda)
}

Corresponding author: Marie-Catherine Gagnon-Dufresne

Email: marie-catherine.gagnon-dufresne@umontreal.ca

\begin{abstract}
Background: In Uganda, almost half of children under 5 years old suffer from undernutrition. Community-based management of acute malnutrition (CMAM) is recognized as an effective strategy for tackling this important global health issue. However, evaluations of CMAM programs are inconsistent and largely based on biomedical and behavioral health models, failing to incorporate structural factors influencing malnutrition management. Using an intersectional lens would allow to investigate the complex social processes shaping children's care in CMAM programs. The aim of this evaluation was to understand and describe factors influencing malnutrition management in a CMAM program in rural Uganda, situating its findings within their social contexts using an intersectional approach.
\end{abstract}

Methods: This evaluation used qualitative methods to identify determinants linked to caregivers (micro-level), healthcare (meso-level) and societal structures (macro-level) that can influence children's outpatient care. Data were collected from September to December 2019 at a community clinic through observations and interviews with caregivers of malnourished children. Data were coded in NVivo using thematic analysis. Intersectionality informed the interpretation of findings.

Results: We observed 14 caregiver-provider encounters and interviewed 15 caregivers to assess factors hindering outpatient malnutrition management. Findings showed that caregivers had limited understanding of malnutrition and its mechanisms. The counselling offered was inconsistent and information given to caregivers about treatment preparation at home was insufficient. Gender inequality and poverty limited caregivers' access to healthcare and their ability to care of their children. Factors at the micro and meso levels intersected with structural factors to influence malnutrition management.

Conclusion: Results suggest that CMAM programs would benefit from expanding support to caregivers by providing holistic interventions tackling structural barriers to children's care. Using an intersectional approach to program evaluation could support improvement efforts by moving beyond individual determinants to address the social dynamics shaping the outpatient management of malnutrition in low- and middle-income countries.

\section{KEYWORDS}

undernutrition, moderate acute malnutrition, severe acute malnutrition, community-based management of acute malnutrition, social determinants of health, intersectionality, Uganda, subSaharan Africa 


\section{KEY MESSAGE}

Most evaluations of community-based management of acute malnutrition programs adopt biomedical or behavioral health models, while determinants beyond caregivers' choices, behaviors, and practices can influence the outpatient management of child malnutrition. Managers and evaluators of these programs in low- and middle-income countries should also consider healthcare and structural determinants of care, to offer holistic interventions tackling the multifaceted barriers to programmatic success.

\section{KEY MESSAGES}

\section{Key Findings}

- Poverty and gender inequality limited caregivers' access to healthcare and their ability to comply with community-based management of acute malnutrition (CMAM) outpatient protocol.

- Nutritional counseling provided to caregivers was inconsistent, often including contradictory information about the treatment prescribed to children.

- Caregivers of malnourished children had a limited understanding of malnutrition and its underlying mechanisms.

\section{Key Implications}

- CMAM program evaluators should look beyond individual and behavioral factors and consider how healthcare and structural determinants interact with caregivers' behaviors in influencing children's outpatient care.

- CMAM program managers should expand support offered to caregivers by implementing holistic interventions tackling the multilevel barriers to malnutrition management to maximize programmatic success.

- Policymakers in Uganda and other low- and middle-income countries should develop national guidelines to fight malnutrition that seek to address the underlying determinants of child undernutrition, such as food insecurity, poverty, and women's access to education and employment.

\section{INTRODUCTION}

The United Nations Sustainable Development Goals call to 'end hunger, achieve food security and improved nutrition and promote sustainable agriculture' by $2030 .{ }^{1}$ Yet, child malnutrition is still a pressing global health issue, as we are not on track to achieve this goal in less 
than a decade. ${ }^{1}$ Nearly half of all deaths of children under 5 years of age are attributable to undernutrition globally, with low- and middle-income countries bearing much of the burden. ${ }^{2}$ Undernutrition, a common form of malnutrition in children, includes chronic malnutrition or stunting (low height for age), acute malnutrition or wasting (low weight for height), as well as underweight (low weight for age)., ${ }^{2,3}$ In Uganda, child undernutrition is recognized as a public health priority and is a central pillar in various national policies. ${ }^{4-6}$ Although some progress has been made in recent years, it is estimated that $29 \%$ of children under 5 are stunted, $4 \%$ are wasted, and $11 \%$ are underweight. ${ }^{7,8}$ Causes of malnutrition, including undernutrition, are complex. The growing Ugandan population is largely rural (75\%) and nearly two thirds work in agriculture, making rural households particularly vulnerable to environmental fluctuations like droughts and flooding, increasing food insecurity. ${ }^{7-9}$ With $42 \%$ of the population affected by poverty, access to basic sanitary services and to affordable and quality healthcare is limited. ${ }^{8,10}$ High fertility rates, gender inequality, and women's limited access to education and paid employment also worsen food insecurity and malnutrition. ${ }^{7,8,11}$ Other drivers of child malnutrition include the high disease burden, especially diarrhea and malaria, and poor infant and young children feeding practices. ${ }^{8}$ This suggests that interventions tackling malnutrition must be multisectoral and multifaceted, and that limited access to healthcare for the most vulnerable populations restricts the potential of hospital-based strategies.

The World Health Organization (WHO) and other international agencies have recognized community-based management of acute malnutrition (CMAM) as a promising strategy to address moderate and severe acute malnutrition in children under 5 in resource-poor settings, prompting its implementation in more than 60 countries. ${ }^{12}$ CMAM includes community outreach, outpatient management of moderate acute malnutrition (MAM) and severe acute malnutrition (SAM) without complications, provision of ready-to-use therapeutic food (RUTF), nutritional counseling, and 
inpatient treatment of cases with medical complications. ${ }^{12,13}$ The goal of such program is to decentralize malnutrition management so most cases can be treated at home. ${ }^{12}$

Evaluations examining the implementation and impacts of CMAM programs are inconsistent and assess a wide array of components to explain why children's care is suboptimal. ${ }^{14-}$ 17 These evaluations generally adopt behavioral or biomedical approaches to study malnutrition management, emphasizing determinants of health such as biology or individual choices, practices, and behaviors. For instance, some evaluations examine factors associated with primary caregivers' behaviors, such as sharing or selling RUTF, ${ }^{14,18-20}$ feeding children enough food or giving complementary feedings in addition to RUTF, ${ }^{14,21}$ and sanitation and hygiene practices. ${ }^{22}$ Others investigate children's comorbidities, ${ }^{14,23,24}$ and treatment compliance. ${ }^{23,25}$ While these factors can influence how malnourished children's conditions are managed, it would be beneficial to incorporate societal determinants of health when evaluating these programs. ${ }^{26}$ Intersectionality represents a useful framework to do so, highlighting how social identities of marginalized caregivers can interact with societal factors and structural inequalities to influence children's care. Intersectionality allows for the investigation of the complex interactions of micro, meso, and macro determinants in shaping the outpatient management of malnutrition. ${ }^{26-28}$

In 2019, we conducted an evaluation of a CMAM program delivered by a community health clinic in rural Uganda to identify and describe factors hindering the adequate management of child malnutrition, from observations of the program's delivery and interviews with caregivers. This article reports the results of this evaluation and situates findings within their social contexts using an intersectional approach. We discuss micro, meso and macro factors - determinants linked to caregivers, healthcare, and societal structures, respectively - that could explain malnutrition management in this program. 


\section{PROGRAM DESCRIPTION}

Located in the Eastern region of Uganda, Soft Power Health (SPH) is a not-for-profit organization aimed at providing health education and affordable primary healthcare to rural and underserved communities in the Jinja district and surrounding villages. ${ }^{29}$ SPH's Allan Stone community health clinic runs a CMAM program for children with moderate and severe acute malnutrition. The program offers nutritional counseling to caregivers of malnourished children and provides high energy milk (HEM), a homemade mix of powdered milk, sugar, and oil, as treatment for malnutrition.

The program has three stages. First, children's anthropometric measurements are taken at the triage station. Second, caregivers are sent for a consultation with a doctor for confirmation of diagnosis or follow-up, and for the prescription of HEM according to children's age and weight. Third, the kitchen personnel distribute HEM to caregivers and explain how to prepare the treatment at home. Program personnel include triage officers, doctors, nurses, and support staff. Counseling on child nutrition and care should be provided at each stage by corresponding personnel. Children are expected to return to the clinic every two weeks for the re-evaluation of their nutritional status and followed until their anthropometric measurements indicate malnutrition recovery.

\section{METHODS}

\section{Evaluation design}

We conducted a qualitative process evaluation of Soft Power Health's CMAM program from September to December 2019. The design of the evaluation was developed in collaboration with the managers of the clinic to ensure that it examined program implementation, participants' interactions with the program, and contextual factors influencing implementation. ${ }^{30}$ This evaluation focused on the caregivers of malnourished children enrolled in the program to examine 
program delivery, caregivers' knowledge of malnutrition and their perceptions of the program, as well as contextual factors that may influence malnutrition management. ${ }^{30}$ This allowed the assessment of factors at the micro (caregivers), meso (healthcare) and macro (societal structures) influencing malnutrition management. Data were collected through direct observations of encounters between caregivers and healthcare personnel during program delivery at the clinic, and subsequent semi-structured interviews with caregivers.

\section{Selection and sampling}

We used purposive sampling to recruit 15 caregivers of children between 12 and 59 months old diagnosed with MAM or SAM, enrolled in SPH's CMAM program, and receiving HEM as treatment. The WHO criteria for diagnosis of child MAM and SAM, also used by the clinic, were adopted as inclusion criteria. MAM is defined as a weight-for-height Z-score $<-2$ and $\geq-3$ or a midupper arm circumference $\geq 115$ and $<125$ millimeters. SAM refers to a weight-for-height standard deviation $<-3$ or a mid-upper arm circumference $<115$ millimeters. ${ }^{3,31}$ Exclusion criteria were as follows: 1) children under 1 year old, as they receive a different treatment for malnutrition; 2) children over 5 years old, as the diagnosis criteria differ; and 3) children with cerebral palsy, as they are prescribed HEM as long-term dietary supplement.

All caregivers of eligible children enrolled in the program were approached by an interpreter at the triage station of the program. The interpreter explained the evaluation objectives, and asked caregivers for their oral informed consent to observe their encounters with healthcare providers and participate in a short interview. All health professionals involved in the consultations with the patients and their families also provided their consent for the observations. Before the interviews, participants were asked again for their consent. They were reexplained the evaluation's objectives and described their rights (e.g., to withdraw consent at any time, to take breaks if needed, 
not to answer interview questions, to ask questions to the interviewer throughout the process). They were also assured that their decision to opt out of the interviews would not hinder their participation to the CMAM program and were asked if they had questions. All participants gave their written informed consent in a form written in plain language in Lusoga (local language). The interpreter read the form for illiterate participants, who signed with a thumbprint to give consent.

\section{Data collection and translation}

A total of 14 observations and 15 interviews with caregivers were conducted ( 2 caregivers came with the same child but were interviewed separately as they shared custody). Non-participant observations were conducted to understand the encounters between caregivers and providers during the different stages of the program. After documenting the CMAM program's curriculum and discussing with SPH's managerial team, we created an observation guide to examine how the program was delivered at each of its stages (Table 1). Caregivers were observed directly after they were recruited to ensure that all stages of the CMAM program could be observed. Observations thus provided the opportunity to examine factors associated with delivery and counselling that could influence children's care. ${ }^{32}$

Table 1. Information assessed by non-participant observations of patient-provider encounters the CMAM program

\begin{tabular}{|c|c|c|}
\hline \multicolumn{3}{|c|}{ CMAM components observed } \\
\hline $\begin{array}{c}\text { Triage station (triage } \\
\text { officers) }\end{array}$ & Doctor consultation (doctors) & $\begin{array}{c}\text { Distribution of HEM (support } \\
\text { staff) }\end{array}$ \\
\hline $\begin{array}{l}\text { Number of visits to the clinic } \\
\text { as part of the CMAM program }\end{array}$ & $\begin{array}{l}\text { Validation of anthropometric } \\
\text { measurements from patient card }\end{array}$ & $\begin{array}{l}\text { Updating patient anthropometric } \\
\text { data in the HEM register }\end{array}$ \\
\hline $\begin{array}{l}\text { Relationship of caregivers to } \\
\text { children enrolled in the } \\
\text { program }\end{array}$ & $\begin{array}{l}\text { Physical examination to look for } \\
\text { visible signs of malnutrition and } \\
\text { discussion with caregivers }\end{array}$ & $\begin{array}{l}\text { Preparation of HEM formula with } \\
\text { caregivers }\end{array}$ \\
\hline $\begin{array}{l}\text { Recording of all } \\
\text { anthropometric measurements } \\
\text { required }\end{array}$ & $\begin{array}{l}\text { Information on the extent and } \\
\text { content of counseling provided (if } \\
\text { any) }\end{array}$ & $\begin{array}{l}\text { Explanation of HEM preparation } \\
\text { and treatment plan to caregivers }\end{array}$ \\
\hline
\end{tabular}




\begin{tabular}{|l|l|l|}
\hline $\begin{array}{l}\text { Information on the extent and } \\
\text { content of counseling provided } \\
\text { (if any) }\end{array}$ & $\begin{array}{l}\text { Time allotted for questions by } \\
\text { doctors, questions asked by } \\
\text { caregivers and answers provided }\end{array}$ & $\begin{array}{l}\text { Information on the extent and } \\
\text { content of counseling provided (if } \\
\text { any) }\end{array}$ \\
\hline $\begin{array}{l}\text { Time allotted for questions by } \\
\text { program staff, questions asked } \\
\text { by caregivers and answers } \\
\text { provided }\end{array}$ & $\begin{array}{l}\text { Knowledge of malnutrition } \\
\text { demonstrated by doctors }\end{array}$ & $\begin{array}{l}\text { Time allotted for questions by } \\
\text { support staff, questions asked by } \\
\text { caregivers and answers provided }\end{array}$ \\
\hline $\begin{array}{l}\text { Knowledge of malnutrition } \\
\text { demonstrated by program staff }\end{array}$ & $\begin{array}{l}\text { Prescription of HEM, calculation } \\
\text { of formula distribution using the } \\
\text { WHO chart, explanation of } \\
\text { treatment plan to caregivers }\end{array}$ & $\begin{array}{l}\text { Knowledge of malnutrition } \\
\text { demonstrated by doctors }\end{array}$ \\
\hline $\begin{array}{l}\text { Comments heard and other } \\
\text { observations }\end{array}$ & $\begin{array}{l}\text { Comments heard and other } \\
\text { observations }\end{array}$ & $\begin{array}{l}\text { Comments heard and other } \\
\text { observations }\end{array}$ \\
\hline
\end{tabular}

Following these observations, semi-structured interviews were conducted in Lusoga and English with the same caregivers, to assess factors linked to practices, knowledge, and living conditions that could influence outpatient malnutrition management, as well as their perceptions of the CMAM program, including the counselling and HEM. Based on UNICEF's conceptual framework on the determinants of malnutrition and on SPH's program characteristics, an interview guide was developed in partnership with SPH's managerial team (Table 2). ${ }^{33}$ Observation and interview guides were validated with health professionals outside the CMAM program to ensure that the elements investigated were accurate, understandable, and relevant. At the end of each interview, caregivers were shown a pictogram tailored to their children's HEM treatment (i.e., quantity and intervals between feeds) explaining how to prepare the formula. If caregivers were unable to describe how to prepare HEM, they were referred to program staff for further counseling. Interviews were conducted in a safe and quiet room away from the main clinic area and lasted between 12 and 29 minutes.

Table 2. Information assessed by interviews with caregivers of children enrolled in the CMAM program

\begin{tabular}{|c|c|}
\hline \multicolumn{2}{|c|}{ Interviews with caregivers of malnourished children } \\
\hline Themes & Information asked \\
\hline
\end{tabular}




\begin{tabular}{|l|l|}
\hline $\begin{array}{l}\text { Sociodemographic } \\
\text { characteristics of } \\
\text { caregivers and children }\end{array}$ & $\begin{array}{l}\text { - Village of residence and distance from the clinic } \\
\text { - Age, gender, marital status, religious affiliation, education, employment, and } \\
\text { main source of income of caregivers } \\
\text { - Age, gender, birth order and comorbidities of malnourished child, } \\
\text { relationship to the child, number of children in the family } \\
\text { - Duration of enrollment in the program and HEM treatment start date }\end{array}$ \\
\hline $\begin{array}{l}\text { Care and feeding } \\
\text { practices and knowledge } \\
\text { of malnutrition }\end{array}$ & $\begin{array}{l}\text { - Understanding of malnutrition and of signs and causes of malnutrition } \\
\text { - Identification of enablers and barriers to children's nutritional health } \\
\text { - Children's diet and care, hygiene and feeding practices }\end{array}$ \\
\hline $\begin{array}{l}\text { Knowledge, practices, } \\
\text { and perceptions of HEM }\end{array}$ & $\begin{array}{l}\text { - Understanding of HEM and how to prepare the treatment at home } \\
\text { - Perception of HEM and complementary feeding practices }\end{array}$ \\
\hline $\begin{array}{l}\text { Information on } \\
\text { counseling received and } \\
\text { perceptions of CMAM } \\
\text { program }\end{array}$ & $\begin{array}{l}\text { - Takeaways from visits at the clinic and the CMAM program } \\
\text { - Nature of counseling and advice received from CMAM program staff } \\
\text { - Information that was most helpful to caregivers and gaps in information }\end{array}$ \\
\hline Preparation of HEM & $\begin{array}{l}\text { - Pictogram showed to caregivers to describe preparation of HEM treatment } \\
\text { - Understanding of how to prepare HEM treatment at home (i.e., intervals } \\
\text { between feeds, amount of treatment given, other relevant information) }\end{array}$ \\
& - Referral to further counseling if caregivers have remaining concerns
\end{tabular}

Lusoga was the mother tongue of all participants. Therefore, observations and in-depth interviews were conducted in collaboration with a local interpreter. The interpreter was trained by the first author on the conduct of direct observations and translation with conceptual equivalence, aiming to provide technically and conceptually accurate translation by including sociocultural and contextual knowledge. ${ }^{32,34}$ The interpreter provided whisper translation of the exchanges between health professionals and caregivers during the observation phase, and translated all interviews in real time. The interpreter validated her initial translation with the recorded interviews, increasing precision and validity of translation. ${ }^{34-36}$

\section{Data analysis}

This study used interpretive description to analyze interview and observation data, allowing for a rich analysis of children's care within the program. It contributed to situating caregivers' testimonies in their sociocultural context in a way that can be useful for improving program practices. ${ }^{37}$ Data were transcribed in English and imported in NVivo (released in March 2020). ${ }^{38}$ 
Interview data were submitted to thematic analysis. ${ }^{39}$ Analysis was done in a deductive and inductive manner to examine caregiver/household, healthcare, and structural determinants of care from an intersectional perspective, while also allowing for the development of codes directly from the data. ${ }^{40,41}$ Notes from observation were used to validate the analysis and interpretation of interview data. Themes were confronted to the relevant literature in a logic of data triangulation between direct observations, semi-structured interviews and existing literature. ${ }^{42}$

\section{Ethical approval}

This program evaluation was conducted by the first author as part of a graduate internship. Ethics approval was granted by Mbarara University of Science and Technology's Research Ethics Committee in Uganda (MUST-2021-131). An exemption was granted following evaluation of the project by the University of Montreal's Ethics Committee for Science and Health Research (CERSES) following Article 2.5 of the Panel on Research Ethics of the Government of Canada. This project was conducted in an ethical and responsible manner. Oral and written informed consent was obtained from all participants in their mother tongue. Names of research participants were anonymized to protect their confidentiality.

\section{RESULTS}

We interviewed 15 caregivers of children with malnutrition. The mean age of caregivers was 33 years (range $=21-56$ ), and most of them were women (87\%). All of them lived in rural areas. The average highest school grade completed was $6^{\text {th }}$ grade $\left(\right.$ range $\left.=0-12^{\text {th }}\right)$. In total, 16 children were included in the study as some caregivers came with more than 1 child. Caregivers had 3 children on average (range=1-8). Children had been enrolled in the CMAM program for an average of 2 months (range $=0-12$ ). 
Based on the analysis of the 15 interviews with caregivers, 3 themes were developed. The first theme presents factors related to caregivers' knowledge and practices (micro-level) that may influence the outpatient management of children's malnutrition. The second theme identifies healthcare (meso-level) factors that can impact the care of children in the program. The third theme describes the structural (macro-level) forces that may hinder children's care. These themes highlight the interrelated determinants of malnutrition management within CMAM programs.

\section{Lacking the knowledge to support their children: Determinants of malnutrition management related to caregivers (micro-level)}

\section{Having a limited understanding of malnutrition}

When asked about their understanding of malnutrition, caregivers explained what it meant to them and discussed signs of malnutrition in children. The primary sign of malnutrition identified by caregivers was weight loss, as many recognized that losing weight led to seeing the children's bones under their skin. Most participants described malnutrition as "thinning out" or "growing small." Accordingly, a woman in her 50's (P05) explained how she understood that her child relative was malnourished: "The signs that showed me that she had got malnourished were that I saw her thinning out, with no flesh onto the bones." A woman in her 20's (P07) described malnutrition in a similar way: "There are some kids in this case of malnutrition, you can find them when they have gone small, and they have no flesh. You just see bones." Although caregivers interviewed could generally identify weight loss as a sign of malnutrition, many of their children had symptoms other than weight loss. Only a few participants named other signs of malnutrition, such as "swelling of the cheeks," "enlarging of the abdomen," "yellowing of the face" or "a change of color of the hair." Caregivers often asked for more information on malnutrition and how to 
support their children, suggesting that their health literacy was limited and that they would benefit from better understanding this condition.

Not grasping the mechanisms that bring malnutrition

Caregivers discussed causes of malnutrition and factors that contribute to improving children's nutritional status. Caregivers named many perceived causes of malnutrition that were not necessarily linked with nutrition such as "sleeping well," "giving leftover food," "the body being hot," "coldness," "delaying seeking medical attention," and "malaria." Nevertheless, all but one participant identified inappropriate feeding habits as the primary cause of malnutrition. A woman in her 50's (P08) explained that not eating nutritious food could cause malnutrition: "What brings malnutrition: this child not feeding well or not eating food which can help build the body." A woman in her 20's (P02) talked about ways in which she could help her children recover from malnutrition: "According to me, the way I think, it means giving enough food to this child and having different meals, like having a balanced diet." Although all participants stressed their role as caregivers in supporting their children to recover from malnutrition, the majority mentioned mostly feeding their children on a carbohydrate diet. Posho (cornmeal porridge), matooke (boiled green banana), rice and potatoes were the staple food most named by caregivers: all participants named at least one of these food items and almost half only discussed carbohydrates. For instance, a woman in her 50's (P09) explained her child relative's daily diet, only consisting of carbohydrates: "There are many foods, like posho, potatoes, matooke. Sometimes, the father also brings in rice." Data suggest that while caregivers could identify perceived causes of malnutrition, they did not fully grasp the mechanisms causing malnutrition or know concrete ways to support their children's nutritional health. 
medRxiv preprint doi: https://doi.org/10.1101/2021.09.01.21262681; this version posted September 5, 2021. The copyright holder for this preprint (which was not certified by peer review) is the author/funder, who has granted medRxiv a license to display the preprint in perpetuity.

It is made available under a CC-BY-NC-ND 4.0 International license .

\section{Relying on medical care and HEM to treat malnutrition}

When asked to talk about factors supporting nutritional health, many emphasized the importance of giving HEM and seeking medical attention. Caregivers seemed to rely on the CMAM program to help their children, minimizing their agency in making changes. Many caregivers blamed themselves, mentioning they used to "neglect the child" or "not take good care" before entering the program. A woman in her 50's (P05) said that "what will help her is taking the child to see the medical personnel, they do check-ups on her [...] and giving treatment so that the child will get fine." Similarly, a man in his 30's (P10) said that "when sickness does not get cured, the child does not get well." Many participants thus named HEM as the key solution to malnutrition. A woman in her 20's (P06) stressed how HEM was beneficial for her child: "For me, I agree that the milk they are giving this child is helping him improve. And I see that he is looking else. I brought him, and you could look at him and see that he's not well." Data show participants' reliance on medical care, suggesting that some might undervalue their capabilities as caregivers and underemphasize complementary practices that can be done at home to help their children recover from malnutrition.

\section{Being unequipped to make informed decisions: Healthcare (meso-level) determinants of malnutrition management}

\section{Difficult knowledge transfer and inconsistent counseling}

The counseling provided to caregivers by clinic personnel participating in the CMAM program varied greatly. This was assessed during observations of patient-provider encounters and confirmed during interviews. The frequency, content, and intensity of counseling was inconsistent across stages and health professionals. Counseling sessions most often addressed recommendations on how to have a balanced diet, when to feed children, and examples of local foods to give them. 
medRxiv preprint doi: https://doi.org/10.1101/2021.09.01.21262681; this version posted September 5, 2021. The copyright holder for this preprint (which was not certified by peer review) is the author/funder, who has granted medRxiv a license to display the preprint in perpetuity.

It is made available under a CC-BY-NC-ND 4.0 International license .

For instance, like this woman in her 20's (P12), many caregivers confirmed this emphasis put on diet when remembering counseling: "I was told to cook food [...] Taking care, giving the treatment that they have given me, and also giving food all the time." However, others mentioned receiving very little or no nutritional counseling. For instance, a woman in her 20s (P01) explained that in her previous appointment, when her children were first admitted to the CMAM program, she did not receive much counseling: “Last time when I came, I didn’t get enough education. It's today that I have got more health education." Similarly, another woman in her 20's (P07) who had previously dropped out of the program and returned for the first time after months of absence said that she was not counseled: "There is nobody who educated me [...] They taught me how to cook only [...] I also had the first teaching on the other side about hygiene." Thus, in line with our program observations, counseling offered to caregivers was inconsistent. Knowledge transfer also seemed inefficient, as caregivers did not seem to fully understand the information that was shared with them by program staff. Many participants indeed expressed their uncertainty about malnutrition and asked for further information to improve their children's diet during the interviews.

\section{Confusion caused by conflicting information on HEM treatment}

All participants had a positive perception of HEM, and many mentioned that HEM was "better than cow's milk," 'built the body" and "helped children gain energy." However, most were hesitant to answer when asked to describe the treatment. A woman in her 20's (P06) explained that she did not know what HEM was made of: “Ah! For me I don't know, but they say they put that building food in the milk." Likewise, a woman in her 40's (P04) who was caring for her niece expressed not understanding what was HEM: "This milk you are giving me? I don't know it." Additionally, many participants were confused when asked to explain how to prepare the HEM 
treatment. Participants were sometimes given differential information about the prescribed amount of HEM and feeding times by doctors and other program personnel. For example, a woman in her 20's (P07) expressed not being taught how to prepare HEM: “I wasn’t told [...] Nurse, how long does that milk take to boil? I forgot asking." Similarly, a woman in her 50's (P08) was unsure about how to measure the right quantity of HEM for her child relative:

This measuring part, like measuring milk... I was told to measure the baby cups, these ones having the measurements. What if I just give the estimated amount? Now, this one is a big child, what if I use a cup? Because she can't finish the big cup, but what if I estimate the amount? What if I don't use the real measurements, but I estimate the real amount she has been taking before. How is it?

Importantly, given the limited access to a stable income and education, some participants did not own baby bottles with measurements, and did not know how to read, making it impossible for them to comply with the treatment prescribed. Yet, few participants were asked about their understanding of the treatment plan by program staff, while they would have benefited from more information about preparation of the prescribed HEM treatment at home.

\section{Trying to overcome social inequities: Structural (macro-level) determinants of malnutrition management}

\section{Poverty hindering access to healthcare and compliance with CMAM protocol}

Many caregivers named poverty as an obstacle to the management of their children's condition. One way in which economic insecurity impacted malnutrition was by restricting access to healthcare. Most of the participants interviewed lived far from the clinic and had to pay up to \$8.45 USD for a round trip using public transport, even if many had no income or faced precarious working conditions. A woman in her 20's (P01) explained delaying to seek medical attention for her child's malnutrition, not having enough money to pay for transport: "When he feels sick, you may lack money for transport to bring the child to the clinic. Like last time, I was supposed to come 
back on [a specific day] but money was a problem." Another woman in her 20's (P02) who had been receiving free health services and HEM through the CMAM program expressed being scared because the staff told her she would soon have to start to pay for treatment:

I [received nutritional counseling]. But right now, since I'm not working and I do not have another job, I don't have money. And now, since they are saying that they are going to stop [my children] from getting milk, and yet, I don't have any money in my pockets, and I don't have anywhere to start from to get money, and I've been relying on this milk.

Another woman caregivers (P05) mentioned that poverty hindered her ability to comply with the recommendations of the program as she did have enough money to buy a sufficient variety of food to feed her child relative with a balanced diet: "Maybe I can [help my child get better], but right now I don't have enough money. Still, I can buy what I can afford.” Consequently, poverty limited access to healthcare and hindered treatment compliance for participants, as they often could not afford to pay for transport, treatment, or diverse foods recommended by program personnel to support their malnourished children.

\section{Gender inequality limiting caregivers' ability to care for malnourished children}

Out of 15 participants interviewed, 13 were women, most of whom did not access education beyond primary school and were not employed outside the home. Women respondents were primary caregivers and responsible for much of child rearing duties, often having many children to care for. In contrast, the two male respondents had secondary education and were expected to support their family financially. A man in his 30's (P13) explained that he and his wife were constantly arguing and that their misunderstandings resulted in them neglecting to care for their child: "The relationship between me and the mother of this child, it may affect the child [...] The more I keep on arguing with the mother, it affects this child." Women also mentioned that difficult family situations impacted their ability to manage their children's malnutrition. For instance, a 
medRxiv preprint doi: https://doi.org/10.1101/2021.09.01.21262681; this version posted September 5, 2021. The copyright holder for this preprint (which was not certified by peer review) is the author/funder, who has granted medRxiv a license to display the preprint in perpetuity.

It is made available under a CC-BY-NC-ND 4.0 International license .

woman in her 30's (P15) who had many children, explained that people in her village provided food for her family because she did not have an income. She said that while her husband occasionally came back to force her to have other children, he did not support his family:

The man is not at home. He has taken a long time without coming home. He ran away from home, and he has spent now years [without coming back] [...] He just forced me to have sex. Then, I gave birth to this one.

She also expressed that while many of her children were malnourished, she did not have money to bring them all to the clinic. Other women similarly discussed being left to provide for their children alone. For example, a woman in her 20's (P01) said that she moved out of her husband's home because he "did not give [her] care" and that her financial situation was "very bad." Another woman (P12) mentioned that her husband was rarely present: "I stay with him, but still... I stay with him for a short time. [...] He's having two wives so he's not ever at home." Similarly, a woman in her 20's (P02) discussed seeking help from the clinic's domestic violence counselor to ensure she could provide treatment for her children: "I went to the [domestic violence] counselor who came and spoke to [the CMAM program personnel], and they made for me a receipt indicating that I will be taking milk for free, and also the transport included." Therefore, women's financial dependence upon their male partners or difficult family situations seemed to hinder their ability to respond to their children's nutritional needs and access services required to overcome malnutrition.

\section{DISCUSSION}

This qualitative evaluation provides rich data on the care of malnourished children enrolled in a CMAM program in rural Uganda. This article offers novel insight on the issue of child malnutrition in the context of CMAM, providing more information on the multifaceted determinants influencing the successful management of malnutrition. Three main themes were developed, indicating that caregiver/household, healthcare, and structural factors can shape how 
children fare in CMAM programs. These findings should be used to inform the implementation and evaluation of such programs in low- and middle-income countries (LMICs), specifically when developing the counseling curriculum and complementary social interventions to ensure that enrolled children can thrive. This evaluation is significant as, to the best of our knowledge, it is the first to use intersectionality to situate its findings within their social contexts. It shows that micro (caregiver/household), meso (healthcare), and macro (structures) determinants intertwine, suggesting that they should all be considered in the design and evaluation of CMAM programs.

Many evaluations of CMAM programs adopt biomedical or behavioral health approaches, neglecting to explore factors beyond the individual influencing malnutrition management. ${ }^{43}$ It has been argued elsewhere that an intersectional framework should be used when assessing health interventions to grasp how individual dynamics intersect with structural factors to shape patterns of health vulnerabilities and inequities. ${ }^{44-48}$ In our evaluation, we found that caregivers' social identities, including their gender, literacy level, living conditions, and socioeconomic status, interacted with broader systems of oppression such as poverty, gendered norms and household inequalities, women's limited access to education and employment, and lack of social protections. These structural barriers increased the vulnerabilities of caregivers and their families, limiting their agency to become food secure, access healthcare, and care for their malnourished children. ${ }^{49}$ CMAM programs should consider these barriers and examine how societal determinants of care can hinder caregivers' capacity to uphold CMAM protocols. ${ }^{50}$

The first theme demonstrated that determinants related to caregivers' characteristics and practices could influence how malnutrition was managed in community-based programs. Our results are consistent with other evaluations of CMAM programs in LMICs showing that caregivers in low-resource settings may have limited understanding of malnutrition and its complex mechanisms. ${ }^{51-54}$ Our findings showed that most caregivers perceived undernutrition as being 
associated with weight loss and caused by poor feeding habits. Interestingly, a study conducted in India concluded that caregivers did not perceive malnutrition as a disease and were less likely to consult health professionals if their children were 'only skinny'. ${ }^{55}$ This suggests that low health literacy regarding malnutrition can impede caregivers' ability to detect the condition early, recognize its severity, and seek medical care. This result is worth considering as this could also influence treatment compliance and outpatient management of malnutrition.

We also found that caregivers often blamed themselves for not properly caring for their children, relying on medical care and HEM as solutions to malnutrition. This echoes the findings of a study on the perceptions of food in Uganda, arguing that food-related research should try to deconstruct the 'gendered and classed discourses of blame,' in which women are blamed for family feeding practices. ${ }^{44}$ Other evaluations of CMAM programs conclude that higher levels of maternal education and employment were associated with better nutrition and feeding practices, such as meal frequency or dietary diversity. ${ }^{21,51,56}$ This suggests that increasing gender equality and promoting non-stigmatizing strategies to improve women's empowerment would be beneficial for malnutrition management.

Our second theme identified factors associated with program implementation that can shape the outpatient management of malnutrition. Consistent with our observations of patient-provider encounters, interviews showed that caregivers received inconsistent counseling, as well as insufficient (and sometimes contradicting) information about HEM preparation. This builds on findings from other evaluations of CMAM programs highlighting that healthcare providers do not always adhere to protocols, and that staff training and supervision are critical to programmatic success. ${ }^{13,19,23}$ Other studies have recommended implementing thorough nutritional counseling, stressing the importance of integrating preventive and curative advice for effective outpatient rehabilitation. ${ }^{14,57}$ Their findings are significant for our evaluation, helping to explain why 
caregivers had limited understandings of malnutrition and struggled to describe and comply with the treatment prescribed. Strengthening knowledge transfer in CMAM programs to ensure that treatment preparation is well explained to caregivers would likely improve children's care.

Our third theme outlined structural barriers hindering the ability of caregivers to adequately manage their children's malnutrition. Caregivers, who were mostly women, stressed that poverty was an obstacle to follow CMAM protocols, limiting their ability to pay for transport, seek medical care, and buy a diverse diet for their children. Women's lack of access to education and employment increased their financial dependency upon their husbands and left them in precarious situations when they were unmarried. While many studies on malnutrition highlighted that poverty and maternal sociodemographic characteristics could influence children's nutritional status, ${ }^{11,54,58}$ few evaluations of CMAM program consider societal determinants of health in their analysis. Many studies on nutrition nevertheless recommended assessing economic and food needs of entire households, family dynamics, domestic violence, and women empowerment. ${ }^{13,18,59,60}$ Understanding caregivers' living contexts can thus contribute to better evaluating how children fare in CMAM programs. This has important implications for practice, suggesting that these programs should adopt holistic approaches to simultaneously address family circumstances that can affect children's nutritional trajectories.

\section{Limitations}

There were several limitations to our evaluation. First, although intersectionality guided data analysis, it did not inform the recruitment and interview phases of the evaluation, resulting in the sample not including individuals from stigmatized groups, people with disabilities, people from religious or ethnic minorities, or people living in urban settings. Second, it is possible that caregivers felt compelled to participate to the evaluation as the first author was a foreigner, despite 
our efforts to obtain informed consent, explaining to caregivers that refusing to participate would not impact their participation in the program. Third, because the design and conduct of the evaluation was led by a western evaluator, some sociocultural references might not have been fully grasped during data analysis. Nevertheless, the first author was immersed in the evaluation context for a prolonged period. Close collaboration with local healthcare personnel and a trained interpreter contributed to minimizing these issues by ensuring that the evaluation was conducted ethically, and that its content was culturally appropriate and respectful.

\section{CONCLUSION}

CMAM is a well-known and promising approach for addressing child undernutrition in lowresource settings. ${ }^{61} \mathrm{We}$ believe that CMAM programs could be improved by extending their scope beyond caregivers' feeding practices and care behaviors. These programs should strengthen their counseling curricula to ensure that all caregivers receive sufficient information on outpatient care and that their concerns are addressed. Counseling should also be used to screen for structural vulnerabilities of caregivers and households, seeking to tackle multilevel barriers to children's care. CMAM programs being often delivered by non-governmental organizations or community health clinics providing primary healthcare, caregivers could be referred to partner services targeting chronic food insecurity, poverty, domestic violence, and family planning, as well as women's literacy, employment, and empowerment. We hope that the findings from this evaluation contribute to encouraging CMAM program providers to develop tailored responses to the needs of households, incorporating complex interventions to address societal determinants of health to promote caregivers' empowerment and equitable access to care. ${ }^{50,62}$ Future research should seek to better understand how fathers' involvement can contribute to improving children's care, and explore avenues for collaborations of CMAM programs with other organizations providing 
medRxiv preprint doi: https://doi.org/10.1101/2021.09.01.21262681; this version posted September 5, 2021. The copyright holder for this preprint

(which was not certified by peer review) is the author/funder, who has granted medRxiv a license to display the preprint in perpetuity.

It is made available under a CC-BY-NC-ND 4.0 International license.

complementary services to their target populations. As we step into the last decade of the Sustainable Development Goals, it is critical that CMAM programs in low- and middle-income countries strengthen their delivery and involve multidisciplinary teams to support families in accessing the resources needed to tackle the fundamental causes of undernutrition. 


\section{BIBLIOGRAPHY}

1. United Nations. Goal 2: Zero Hunger. Sustainable Development Goals. Published 2021. Accessed April 28, 2021. https://www.un.org/sustainabledevelopment/hunger/

2. World Health Organization. Malnutrition. World Health Organization. Published 2020. Accessed April 28, 2021. https://www.who.int/news-room/fact-sheets/detail/malnutrition

3. Brown KH, Nyirandutiye DH, Jungjohann S. Management of children with acute malnutrition in resource-poor settings. Nat Rev Endocrinol. 2009;5(11):597-603. doi:10.1038/nrendo.2009.194 4. National Planning Authority. Uganda - Vision 2040. National Planning Authority, Government of Uganda; 2013:136. Accessed April 28, 2021. https://www.greengrowthknowledge.org/sites/default/files/downloads/policy-

database/UGANDA\%29\%20Vision\%202040.pdf

5. National Planning Authority. Third National Development Plan (NDPIII) 2020/21 - 2024/25. National Planning Authority, Government of Uganda; 2020:341. Accessed April 28, 2021. http://www.npa.go.ug/wp-content/uploads/2020/08/NDPIII-Finale_Compressed.pdf

6. Franklin T. Second Uganda Nutrition Action Plan Passed. Office of the Prime Minister, Government of Uganda. Published 2020. Accessed April 28, 2021. https://opm.go.ug/2020/09/29/second-uganda-nutrition-action-plan-passed/

7. Uganda Bureau of Statistics, ICF. Uganda Demographic and Health Survey 2016. The DHS Program; 2018.

8. United States Agency for International Development. Uganda: Nutrition Profile. USAID; 2018:6. https://www.usaid.gov/sites/default/files/documents/1864/Uganda-Nutrition-ProfileApr2018-508.pdf

9. The World Bank. Rural population (\% of total population) - Uganda | Data. The World Bank. $\begin{array}{lllll}\text { Published 2018. } & \text { Accessed } & \text { April } & 28, & 21 .\end{array}$ https://data.worldbank.org/indicator/SP.RUR.TOTL.ZS?locations=UG

10. Mejia-Mantilla C. Poverty \& Equity Brief - Sub-Saharan Africa: Uganda. Published online 2020. Accessed April 28, 2021. https:/databank.worldbank.org/data/download/poverty/33EF03BB-9722-4AE2-ABC7AA2972D68AFE/Global_POVEQ_UGA.pdf

11. Nankinga O, Kwagala B, Walakira EJ. Maternal employment and child nutritional status in Uganda. PLoS ONE. 2019;14(12). doi:10.1371/journal.pone.0226720

12. Reed S, Kouam CE. Evaluation of Community Management of Acute Malnutrition (CMAM): Global Synthesis Report. United Nations Children's Fund; 2013. Accessed April 28, 2021. https://cupdf.com/document/evaluation-synthesis-report.html

13. Shah More N, Waingankar A, Ramani S, et al. Community-Based Management of Acute Malnutrition to Reduce Wasting in Urban Informal Settlements of Mumbai, India: A MixedMethods Evaluation. Glob Health Sci Pract. 2018;6(1):103-127. doi:10.9745/GHSP-D-17-00182 14. Ashworth A. Efficacy and Effectiveness of Community-Based Treatment of Severe Malnutrition. Food Nutr Bull. 2006;27(3_suppl3):S24-S48. doi:10.1177/15648265060273S303

15. Akparibo R, Lee A, Booth A. Recovery, Relapse, and Episodes of Default in the Management of Acute Malnutrition in Children in Humanitarian Emergencies: A Systematic Review. Oxfam; 2017. doi: $10.21201 / 2017.9149$

16. Bitew ZW, Alemu A, Worku T. Treatment outcomes of severe acute malnutrition and predictors of recovery in under-five children treated within outpatient therapeutic programs in Ethiopia: a systematic review and meta-analysis. BMC Pediatr. 2020;20(1):335. doi:10.1186/s12887-020-02188-5 
17. Majamanda J, Maureen D, Munkhondia TM, Carrier J. The Effectiveness of Community-Based Nutrition Education on the Nutrition Status of Under-five Children in Developing Countries. A Systematic Review. Malawi Med J. 2014;26(4):115-118. doi:10.4314/mmj.v26i4

18. Tadesse E, Berhane Y, Hjern A, Olsson P, Ekström E-C. Perceptions of usage and unintended consequences of provision of ready-to-use therapeutic food for management of severe acute child malnutrition. A qualitative study in Southern Ethiopia. Health Policy Plan. 2015;30(10):13341341. doi:10.1093/heapol/czv003

19. Tadesse E, Ekström E-C, Berhane Y. Challenges in Implementing the Integrated CommunityBased Outpatient Therapeutic Program for Severely Malnourished Children in Rural Southern Ethiopia. Nutrients. 2016;8(5):251. doi:10.3390/nu8050251

20. Cohuet S, Marquer C, Shepherd S, et al. Intra-household use and acceptability of Ready-toUse-Supplementary-Foods distributed in Niger between July and December 2010. Appetite. 2012;59(3):698-705. doi:10.1016/j.appet.2012.07.019

21. Kajjura RB, Veldman FJ, Kassier SM. Maternal socio-demographic characteristics and associated complementary feeding practices of children aged 6-18 months with moderate acute malnutrition in Arua, Uganda. J Hum Nutr Diet. 2019;32(3):303-310. doi:10.1111/jhn.12643

22. Stobaugh HC, Rogers BL, Webb P, et al. Household-level factors associated with relapse following discharge from treatment for moderate acute malnutrition. Br J Nutr. 2018;119(9):10391046. doi:10.1017/S0007114518000363

23. Yebyo HG, Kendall C, Nigusse D, Lemma W. Outpatient Therapeutic Feeding Program Outcomes and Determinants in Treatment of Severe Acute Malnutrition in Tigray, Northern Ethiopia: A Retrospective Cohort Study. Bhutta ZA, ed. PLoS ONE. 2013;8(6):e65840. doi:10.1371/journal.pone.0065840

24. Fikrie A, Alemayehu A, Gebremedhin S. Treatment outcomes and factors affecting time-torecovery from severe acute malnutrition in 6-59 months old children admitted to a stabilization center in Southern Ethiopia: A retrospective cohort study. Ital J Pediatr. 2019;45(1):46. doi:10.1186/s13052-019-0642-x

25. Atnafe B, Roba KT, Dingeta T. Time of recovery and associated factors of children with severe acute malnutrition treated at outpatient therapeutic feeding program in Dire Dawa, Eastern Ethiopia. Gopichandran V, ed. PLOS ONE. 2019;14(6):e0217344. doi:10.1371/journal.pone.0217344

26. Birn A-E, Pillay Y, Holtz TH. Textbook of Global Health. Oxford University Press; 2017. doi:10.1093/acprof:oso/9780199392285.001.0001

27. Bowleg L. The Problem With the Phrase Women and Minorities: Intersectionality-an Important Theoretical Framework for Public Health. Am J Public Health. 2012;102(7):1267-1273. doi:10.2105/AJPH.2012.300750

28. Kapilashrami A, Hankivsky O. Intersectionality and why it matters to global health. The Lancet. 2018;391(10140):2589-2591. doi:10.1016/S0140-6736(18)31431-4

29. Soft Power Health. Allan Stone Community Health Clinic. Soft Power Health. Published 2020. Accessed June 28, 2021. https://www.softpowerhealth.org/soft-power-health-clinic.html

30. Moore GF, Audrey S, Barker M, et al. Process evaluation of complex interventions: Medical Research Council guidance. BMJ. 2015;350(mar19 6):h1258-h1258. doi:10.1136/bmj.h1258

31. World Health Organization. WHO Child Growth Standards: Length/Height-for-Age, Weightfor-Age, Weight-for-Length, Weight-for-Height and Body Mass Index-for-Age: Methods and Development. World Health Organization; 2006:312. Accessed April 28, 2021. https://www.who.int/publications-detail-redirect/924154693X

32. Liu F, Maitlis S. Non-participant observation. In: Mills AJ, Durepos G, Wiebe E, eds. 
Encyclopedia of Case Study Research. / Volume 2. SAGE; 2010. Accessed April 28, 2021. http://www.worldcat.org/oclc/811140520

33. United Nations Children's Fund. Improving Child Nutrition: The Achievable Imperative for Global Progress. United Nations Children's Fund (UNICEF); 2013:132. https://data.unicef.org/resources/improving-child-nutrition-the-achievable-imperative-for-globalprogress/

34. Squires A. Methodological challenges in cross-language qualitative research: a research review. Int J Nurs Stud. 2009;46(2):277-287. doi:10.1016/j.ijnurstu.2008.08.006

35. Kapborg I, Berterö C. Using an interpreter in qualitative interviews: does it threaten validity? Nurs Inq. 2002;9(1):52-56. doi:https://doi.org/10.1046/j.1440-1800.2002.00127.x

36. Shimpuku Y, Norr KF. Working with interpreters in cross-cultural qualitative research in the context of a developing country: systematic literature review. J Adv Nurs. 2012;68(8):1692-1706. doi:10.1111/j.1365-2648.2012.05951.x

37. Thorne S, Kirkham SR, MacDonald-Emes J. Interpretive description: a noncategorical qualitative alternative for developing nursing knowledge. Res Nurs Health. 1997;20(2):169-177.

38.QSR International Pty Ltd. NVivo (Released in March 2020).; 2020. https://www.qsrinternational.com/nvivo-qualitative-data-analysis-software/home

39. Braun V, Clarke V. Using thematic analysis in psychology. Qual Res Psychol. 2006;3(2):77101. doi:10.1191/1478088706qp063oa

40. Hankivsky O. Women's health, men's health, and gender and health: Implications of intersectionality. Soc Sci Med. 2012;74(11):1712-1720. doi:10.1016/j.socscimed.2011.11.029

41. Saldaña J. The Coding Manual for Qualitative Researchers. 2nd ed. SAGE; 2013.

42. Nowell LS, Norris JM, White DE, Moules NJ. Thematic Analysis: Striving to Meet the Trustworthiness Criteria. Int J Qual Methods. 2017;16(1). doi:10.1177/1609406917733847

43. Abubakar A. Psychosocial Aspects of Malnutrition Among African Children: Antecedents, Consequences, and Interventions. In: Boivin MJ, Giordani B, eds. Neuropsychology of Children in Africa: Perspectives on Risk and Resilience. Specialty Topics in Pediatric Neuropsychology. Springer; 2013:181-202. doi:10.1007/978-1-4614-6834-9_9

44. Mackay H. A feminist geographic analysis of perceptions of food and health in Ugandan cities. Gend Place Cult. 2019;26(11):1519-1543. doi:10.1080/0966369X.2018.1555148

45. Fortnam M, Hailey P, Atim T, Mbelenga E. Maintains Kenya and Uganda Health and Nutrition Research Protocol: Health System Shock Responsiveness. :114.

46. Nisbett N, Harris J. Equity in Social and Development Studies Research: Insights for Nutrition. Published online June 1, 2018. Accessed February 26, 2021. https://opendocs.ids.ac.uk/opendocs/handle/20.500.12413/13991

47. Uddin MdF, Molyneux S, Muraya K, et al. Gender-Related Influences on Adherence to Advice and Treatment-Seeking Guidance for Infants and Young Children Post-Hospital Discharge in Bangladesh. In Review; 2021. doi:10.21203/rs.3.rs-60106/v3

48. Kapilashrami A, Hill S, Meer N. What can health inequalities researchers learn from an intersectionality perspective? Understanding social dynamics with an inter-categorical approach? Soc Theory Health. 2015;13(3):288-307. doi:10.1057/sth.2015.16

49. Clement F, Buisson M-C, Leder S, et al. From women's empowerment to food security: Revisiting global discourses through a cross-country analysis. Glob Food Secur. 2019;23:160-172. doi:10.1016/j.gfs.2019.05.003

50. Kim JY, Farmer P, Porter ME. Redefining global health-care delivery. The Lancet. 2013;382(9897):1060-1069. doi:10.1016/S0140-6736(13)61047-8

51. Peter ES, Aliyu SH, Hassan RS. Nutrition Assessment and Factors Influencing Malnutrition 
among Children under Five in Adjumani District Uganda. J Adv Med Med Res. Published online March 30, 2019:1-7. doi:10.9734/jammr/2019/v29i330074

52. Isanaka S, Berthé F, Nackers F, Tang K, Hanson KE, Grais RF. Feasibility of engaging caregivers in at-home surveillance of children with uncomplicated severe acute malnutrition. Matern Child Nutr. 2020;16(1):e12876. doi:https://doi.org/10.1111/mcn.12876

53. Mbogo AM, Van Niekerk E, Ogada I, Schubl C. Carers' knowledge of treatment of severe acute malnutrition at Dadaab refugee complex, Kenya: A prospective cohort study. South Afr J Child Health. 2020;14(3):110. doi:10.7196/SAJCH.2020.v14i3.1567

54. Ware SG. Perceptions and experiences of caregivers of severely malnourished children receiving inpatient care in Malawi: An exploratory study. Malawi Med J. 2018;30(3):167. doi:10.4314/mmj.v30i3.7

55. Burtscher D, Burza S. Health-seeking behaviour and community perceptions of childhood undernutrition and a community management of acute malnutrition (CMAM) programme in rural Bihar, India: a qualitative study. Public Health Nutr. 2015;18(17):3234-3243. doi:10.1017/S1368980015000440

56. Humbwavali JB, Giugliani C, Nunes LN, Dalcastagnê SV, Duncan BB. Malnutrition and its associated factors: a cross-sectional study with children under 2 years in a suburban area in Angola. BMC Public Health. 2019;19(1):220. doi:10.1186/s12889-019-6543-5

57. Somassè YE, Dramaix M, Bahwere P, Donnen P. Relapses from acute malnutrition and related factors in a community-based management programme in Burkina Faso: Relapses in a communitybased management programme of acute malnutrition. Matern Child Nutr. 2016;12(4):908-917. doi: $10.1111 / \mathrm{mcn} .12197$

58. Kumeh OW, Fallah MP, Desai IK, et al. Literacy is power: structural drivers of child malnutrition in rural Liberia. BMJ Nutr Prev Health. 2020;3(2). doi:10.1136/bmjnph-2020-000140 59. Sharma AJ, Subramanyam MA. The intersectional role of paternal gender-equitable attitudes and maternal empowerment on child undernutrition in India. medRxiv. Published online February 5, 2021:2021.02.03.21251084. doi:10.1101/2021.02.03.21251084

60. Tette EMA, Sifah EK, Nartey ET, Nuro-Ameyaw P, Tete-Donkor P, Biritwum RB. Maternal profiles and social determinants of malnutrition and the MDGs: What have we learnt? BMC Public Health. 2016;16(1):214. doi:10.1186/s12889-016-2853-z

61.Bhutta ZA, Das JK, Rizvi A, et al. Evidence-based interventions for improvement of maternal and child nutrition: what can be done and at what cost? The Lancet. 2013;382(9890):452-477. doi:10.1016/S0140-6736(13)60996-4

62. Nisbett N, Gillespie S, Haddad L, Harris J. Why Worry About the Politics of Childhood Undernutrition? World Dev. 2014;64:420-433. doi:10.1016/j.worlddev.2014.06.018 